\title{
Submitted: 1 Correlation between portal vein diameter Accepted: and craniocaudal length of the spleen
}

10.11 .2019

Published:

31.12.2019

\section{Keywords}

spleen,

portal vein,

portal hypertension, chronic liver

parenchymal disease, splenomegaly

\author{
Shah Zaman', Syed Amir Gilani², Raham Bacha³, \\ Iqra Manzoor ${ }^{4}$, Zain UI Hasan ${ }^{5}$ \\ ${ }^{1}$ MS Ultrasound, The University of Lahore, Lahore, Pakistan \\ ${ }^{2}$ Dean FAHS, The University of Lahore, Lahore, Pakistan \\ ${ }^{3}$ Department UIRSMIT (FAHS), University of Lahore, Lahore, Pakistan \\ ${ }^{4}$ MPhil Ultrasound, The University of Lahore, Lahore, Pakistan \\ ${ }^{5}$ Ultrasound (Scholar), The University of Lahore, Lahore, Pakistan \\ Correspondence: Iqra Manzoor 1-km off defence road, Lahore, Pakistan; \\ e-mail:iqramanzoor36@gmail.com
}

DOI: $10.15557 / J o U .2019 .0041$

\begin{abstract}
Objective: To determine the correlation between portal vein diameter and spleen size (craniocaudal). Methodology: The study was conducted at the University Ultrasound Clinic, The University of Lahore, Lahore Pakistan from $1^{\text {st }}$ January to $1^{\text {st }}$ July 2013. All the individuals who referred for abdominal sonographic examination, including male, female, older and younger were conveniently included in the study, voluntarily, irrespective of the disease state. Ultrasonographic measurements of the caudocranial length of the spleen and portal vein were carried out on all of the one thousand subjects. The subject position for spleen was supine or right posterior oblique during suspended inspiration and right anterior oblique position for portal vein diameter with quiet respiration. The correlation between the splenic length and portal vein diameter was evaluated. Result: A total of 1000 subjects; $36.9 \%$ females and 63.1\% males aged from 4 to 79 years. The mean splenic length was $10.29 \pm 1.89 \mathrm{~cm}$. The mean portal vein diameter was 10.27 $\pm 1.78 \mathrm{~mm}$. A statistically significant correlation was found between the spleen size and portal vein diameter; the Pearson correlation was significant at the 0.01 level. Conclusion: Portal vein diameter is directly correlated to splenic caudocranial length. A regression formula was developed to measure the splenic length from the calculation of portal vein diameter.
\end{abstract}

\section{Introduction}

The left upper quadrant is most frequently assessed with sonography in patients with enlarged spleen or in the case of trauma ${ }^{(1)}$. The advantages of sonography over other imaging modalities include: portability of the equipment, which allows the sonographer for rapid evaluation of the patient at the bedside, the non-invasive nature of ultrasound, negligible bioeffects, etc. ${ }^{(1)}$ The rapid development and modernization of modalities is another great advantage of ultrasonography ${ }^{(2)}$. Apart from all other advantages, the sonographic examination is interactive, realtime and dynamic ${ }^{(3)}$. Patients could easily be maneuvered, moved, deep breathed, compressed and other provocative measures may be applied. Transducer approach could also be changed, more superficial access could be achieved from deeper access ${ }^{(4)}$. Ultrasound is a multiplanar modality, multiple planes could be acquired instead of relying on a single plane $\mathrm{e}^{(5)}$. Therefore, the importance of ultrasound grows day by day with regard to the evaluation of superficial musculoskeletal structures, nerves, and deep gynecological, obstetrical and abdominal structures $^{(6)}$. Sonography can easily differentiate abdominal structures like liver, gall bladder, pancreases, intestinal walls, abdominal vasculature and spleen, etc. ${ }^{(3)}$ The normal texture of the spleen is very homogeneous, slightly 
more echogenic than the texture of the liver; therefore, pathology or blood collection secondary to a splenic rupture is usually easily identified. We may also examine portal vein status by means of sonography with regard to the portal vein diameter, hypertension, obstruction, thrombus and collaterals ${ }^{(3,7,8)}$.

The spleen is the largest single mass of lymphoid tissue and part of the reticuloendothelial system, it is located in the left upper quadrant of the abdomen, just below the diaphragm ${ }^{(9,10)}$. In embryonic and early fetal life, it actively participates in blood formation (hematopoiesis), however, blood formation activity decreases gradually by the $5^{\text {th }}$ to $6^{\text {th }}$ month of pregnancy, when the spleen discontinues its hematopoietic activities and assumes its adult characteristics ${ }^{(11,12)}$. The spleen plays a major role in the defensive mechanism of the body (reticuloendothelial system) ${ }^{(13)}$. The spleen rarely become the primary site of disease however it is often affected by systemic disease processes ${ }^{(14)}$. Sonographically, like hepatic parenchyma, the splenic parenchyma appears to have a fine uniform homogeneous mid to low-level echo-pattern ${ }^{(15)}$. The texture of the spleen is actually considered to be more echogenic than the one of the liver ${ }^{(16)}$. Like all other abdominal organs, the echogenicity of the spleen increases with development, maturation and enlargement ${ }^{(17,18)}$.

Portal vein (PV) is formed by the joining of superior mesenteric vein and splenic vein while forming porto-splenic confluence, posterior to the pancreas at the level of L2 ${ }^{(19)}$. Portal vein is located 5 to $7 \mathrm{~cm}$ from porto-splenic confluence to the bifurcation in right and left portal vein at porta-hepatis ${ }^{(20,21)}$. The portal vein courses posteriorly to the first portion of the duodenum and then between the layers of the lesser omentum to the porta-hepatis. It bifurcates in the liver into its right and left portal veins and then successively bifurcates to give raise to its terminal branches in the hepatic sinusoids $^{(20,22)}$. Blood of the gastrointestinal tract, (from the lower end of the esophagus to the upper end of the anal canal), pancreas, gallbladder, bile ducts, and spleen is drained by the portal vein to the liver and finally to IVC through hepatic veins ${ }^{(10)}$. The portal vein has an anastomosis with the esophageal veins, rectal venous plexus, and superficial abdominal veins. The liver receives a dual blood supply from the portal vein and the hepatic $\operatorname{artery}^{(23)}$. The portal triad contains branches of the portal vein, hepatic artery, and bile duct. These structures are enclosed within a connective tissue sheath that gives the portal vein an echogenic wall appearance on sonography ${ }^{(24)}$.

The splenic vein is formed by the union of several veins at the splenic hilum. It is subsequently joined by the short gastric and left gastroepiploic veins ${ }^{(25)}$. The splenic vein runs along the posteromedial border of the pancreas. It joins the superior mesenteric vein posterior to the neck of the pancreas to form the portal vein. Additional veins from the pancreas and inferior mesenteric vein drain into the splenic vein ${ }^{(10,26)}$. The splenic vein drains blood from the stomach, spleen, and pancreas into the portal vein ${ }^{(27)}$. In the case of hepatic congestion, resistance occurs in the blood flow of portal vein and ultimately splenic vein ${ }^{(28,29)}$. Pressure build-up in the portal vein due to the excessive amount of blood pooling which causes portal hypertension and ultimately increases in portal vein diameter ${ }^{(30)}$. On the other hand, blood congestion in the spleen causes splenomegaly, therefore splenomegaly is correlated to portal vein diameter ${ }^{(31)}$. Apart from the hepatic fibrosis and congestion, splenomegaly could be caused by a number of diseased conditions, suchas: hematologic disorder, Rheumatologic disorders, infectious diseases, and infiltrative disorders ${ }^{(10)}$. However, hepatic congestion is the most common cause of splenomegaly and portal hypertension ${ }^{(28,32)}$. Therefore, we observed that raises in Portal vein diameter increase the splenic caudocranial length at the same ratio. However, this research was intended to test the hypothesis of a correlation between splenic caudocranial length and portal vein diameter.

\section{Methodology}

A cross-sectional analytical study was performed from $1^{\text {st }}$ January 2013 to $1^{\text {st }}$ July 2013, at the University Ultrasound Clinic, University of Lahore, Gilani Ultrasound Center Lahore, Pakistan, and Shah Doppler Ultrasound Clinic, Pubi (Peshawar), Pakistan. One thousand subjects were enrolled, with no limits as to the age, gender and disease restrictions, except for liver transplant and gastric varices. All the participants were enrolled in this study voluntarily, the procedure was explained to them and written informed consent was obtained. Pre-approval was obtained from the institutional review board (IRB) and the ethical committee of the University of Lahore. Toshiba (Xario) with Convex transducer frequency ranging 3.0-6.0 MHz, having Color \& Power Doppler and Tissue harmonics imaging facilities, Toshiba (Nemio-17) with Convex transducer frequency ranging 3.5-6.0 MHz, having Color \& Power Doppler and Tissue harmonics imaging facilities, and Aloka (SSD 3500) with Convex transducer frequency 3.5 MHz, having Color \& Power Doppler with Tissue harmonics facilities were applied. Data was collected during the allocated period. The spleen size was measured in the longitudinal plane while the patient was lying in supine or right posterior oblique position and scanned during suspended inspiration. Portal vein measurement has been carried out in longitudinal section in supine and right anterior oblique position. The portal vein diameter was measured in quiet respiration at porta hepatis (near Porta hepatis). The diameter was measured by putting the two cursors in the lumen of the portal vein; the walls of the portal vein were excluded from the measurement.

Statistical Package for the Social Sciences (SPSS) version 24 (SPSS 24, IBM, Armonk, Ny, United States of America) software was used for the evaluation of data and formation of graphs. The results were summarized in the form of graphs, tables, and charts. Descriptive data is explained 
Tab. 1. Age, Spleen caudocranial length, and portal vein diameter

\begin{tabular}{|l|c|c|c|c|c|c|c|}
\hline Variable & $\mathbf{N}$ & Range & Minimum & Maximum & Mean & $\begin{array}{c}\text { Standard } \\
\text { deviation }\end{array}$ & $\begin{array}{c}\text { Standard } \\
\text { error }\end{array}$ \\
\hline Age in years & 1000 & 75.00 & 4.00 & 79.00 & 32.5600 & 16.80 & 1.680 \\
\hline Spleen size $(\mathrm{cm})$ & 1000 & 10.16 & 6.84 & 17.00 & 10.2918 & 1.8908 & 0.18 \\
\hline Portal vein $(\mathrm{mm})$ & 1000 & 9.20 & 6.80 & 16.00 & 10.2759 & 1.7875 & 0.17 \\
\hline
\end{tabular}

in the form of frequency, mean and standard deviation. The data was analyzed via Pearson correlation and linear regression analysis.

\section{Results}

A total of 1000 patient, 369 (36.9\%) female and 631 (63.1\%) male participants were included in the study. Patients' ages ranged between 4 and 79 years with the mean of $32.92 \pm 16.8$, and the rest of descriptive measurements are specified in table 1. A statistically strong correlation was found between the caudocranial length of the spleen and portal vein diameter with $P$-value $(0.000)$, the correlation was significant at less than 0.01 level and R-value (0.98), which is near to 1 , represents a strong positive relationship (Tab. 2, Fig. 1). Regression between Splenic caudocranial length and portal vein diameter was calculated at $95 \%$ confidence interval, the values of coefficients, intercept and slope (alpha and beta) and standard deviations with upper and lower limits are presented in Tab. 3.

\section{The formula for the calculation of portal vein diameter:}

To calculate portal vein diameter from the measurement of splenic caudocranial length, the following formula is derived from a simple regression modal as shown in Tab. 3 , Fig. 1.

$$
\mathrm{Y}=\underline{a}+\beta \mathrm{X}
$$

where "y" represents portal vein diameter and " $x$ " represents Splenic craniocaudal length, whereas " $\alpha$ " is intercept 0.737 and " $ß$ " slope is 0.927 .

When putting these values in equation 1 , the following equation will be obtained.

Portal vein diameter in $\mathrm{mm}=$ $0.737+0.927 \times$ Caudocranial length of the spleen

Tab. 2. Correlations between spleen size and portal vein diameter

\begin{tabular}{|l|c|c|c|}
\hline Variables & Correlation & $\begin{array}{c}\text { Spleen } \\
\text { in } \mathbf{~ c m}\end{array}$ & $\begin{array}{c}\text { Portal vein } \\
\text { in } \mathbf{~ m m}\end{array}$ \\
\hline \multirow{3}{*}{$\begin{array}{l}\text { Spleen size } \\
\text { in cm }\end{array}$} & $\begin{array}{c}\text { Pearson } \\
\text { correlation }\end{array}$ & 1 & $0.990^{* * *}$ \\
\cline { 2 - 4 } & Sig. (2-tailed) & & 0.000 \\
\cline { 2 - 4 } & $\begin{array}{c}\text { Number } \\
\text { of subjects }\end{array}$ & 8 & 8 \\
\hline \multicolumn{2}{|l|}{ ** Correlation is significant at the 0.01 level (2-tailed). } \\
\hline
\end{tabular}

Tab. 3. Coefficients for the regression model of splenic size and portal vein diameter

\begin{tabular}{|c|c|c|c|c|c|c|}
\hline \multirow{2}{*}{\multicolumn{2}{|c|}{ Model }} & \multicolumn{2}{|c|}{$\begin{array}{l}\text { Unstandardized } \\
\text { coefficients }\end{array}$} & \multirow{2}{*}{$\begin{array}{c}\begin{array}{c}\text { Standardized } \\
\text { coefficients }\end{array} \\
\text { Beta }\end{array}$} & \multirow{3}{*}{$\begin{array}{c}\mathbf{t} \\
3.742\end{array}$} & \multirow{3}{*}{$\begin{array}{r}\text { Sig } \\
0.000\end{array}$} \\
\hline & & \multirow{2}{*}{$\begin{array}{c}\text { B } \\
0.737 \\
\end{array}$} & \multirow{2}{*}{$\begin{array}{c}\begin{array}{c}\text { Std. } \\
\text { Error }\end{array} \\
0.197 \\
\end{array}$} & & & \\
\hline 1 & (Constant) & & & & & \\
\hline & Spleen & 0.927 & 0.19 & 0.980 & 49.199 & 0.000 \\
\hline
\end{tabular}

Portal vein diameter could easily be calculated from the above equation simply by adding the value of Caudocranial length of the spleen.

Example: If the spleen caudocranial length is $10.0 \mathrm{~cm}$, then the PV diameter will be calculated as follows: 0.737 $+0.927 \times 10=10.0 \mathrm{~mm}$

It is obvious that portal vein diameter increases with an increase in splenic size as shown in a series of ultrasound images (Fig. 2, Fig. 3).

\section{Discussion}

It was an analytical study; the purpose of this research work was to sonographically assess the relationship between spleen craniocaudal length and portal vein diameter that has been observed frequently in ultrasound practice. Realtime sonography is the most accurate and reliable method of assessing the portal vein diameter. Ultrasound is frequently used to examine the spleen to assess its size and texture, it is an easy and non-invasive technique and can be used safely at any age. Studies have proved the high reliability and accuracy of ultrasound in the measurement of the diameter of the portal vein and size of the spleen. The size may inform on the diagnosis and prognosis of disease courses, while the portal vein diameter is useful in evaluating splenic-portal conditions as shown in a series of ultrasound Fig. 2, Fig. 3, Fig. 4.

A study by Rosenberg et al. was carried out to determine the clinical significance of splenic size ${ }^{(33)}$. The authors found that a simple measurement of splenic length served as a guide to spleen size. The authors proposed the upper normal limit of splenic length at $12 \mathrm{~cm}$ for girls aged 15 or older and at $13 \mathrm{~cm}$ for boys aged 15 or older; in another study performed by Dittrich et al., it was observed that there was an approximately linear increase in spleen size, as measured on sonography, in the course of development in the pediatric population and that spleen size correlated best with the body height ${ }^{(34)}$. Konus et al. conducted a study on the pediatric population of 307 subjects and they 


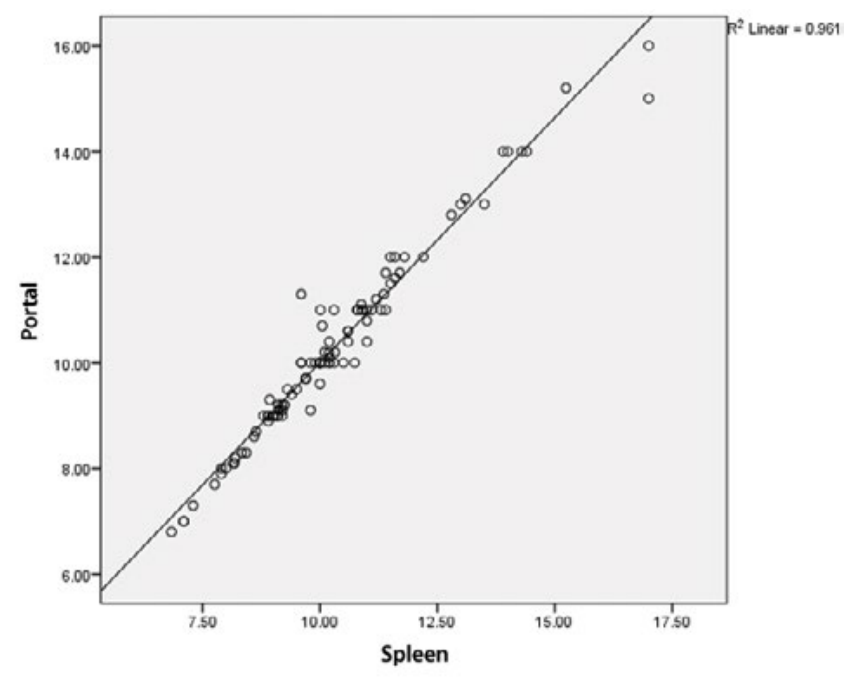

Fig. 1. Scatterplot shows correlation of spleen size in ( $\mathrm{cm})$, portal vein diameter in $(\mathrm{mm})$

found that height is correlated best with spleen length ${ }^{(35)}$. In a study on adults, Frank et al. used conventional sonography to evaluate 793 healthy subjects (17-82 years) and found that $95 \%$ of patients had a splenic length of less

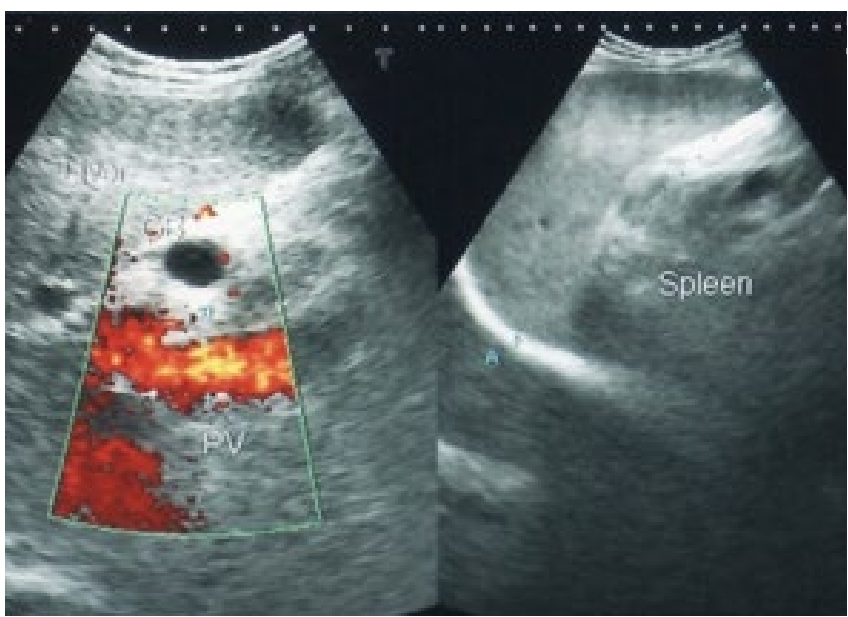

Fig. 2. Spleen size $=15.24 \mathrm{~cm}$, portal vein diameter $=15.2 \mathrm{~mm}$

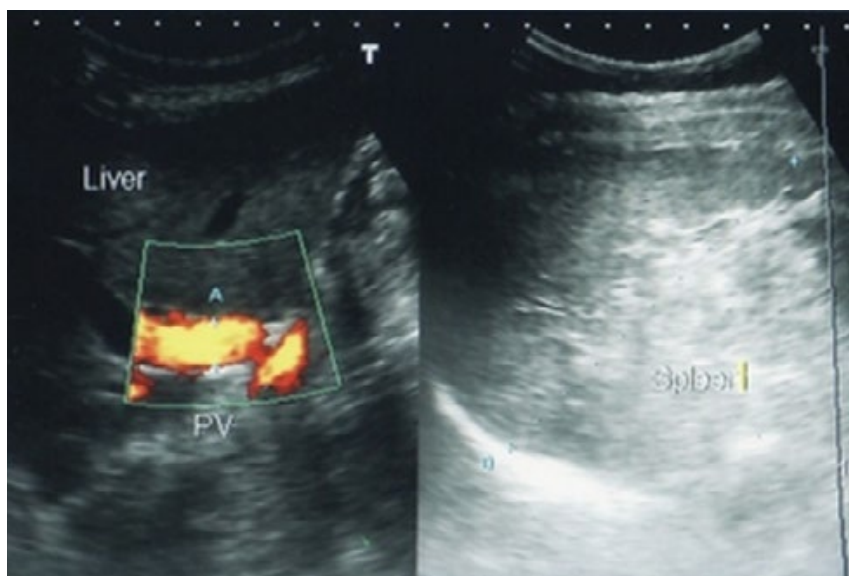

Fig. 3. Spleen size $=10.01 \mathrm{~cm}$, portal vein diameter $=11 \mathrm{~mm}$ than $11 \mathrm{~cm}$, a width (transverse dimension) of less than $7 \mathrm{~cm}$, and a thickness of less than $5 \mathrm{~cm}^{(36)}$. Niederau et al. studied 915 healthy subjects using sonography and determine the mean longitudinal and transverse diameters of the spleen to be $5.8 \pm 1.8 \mathrm{~cm}$ and $5.5 \pm 1.4 \mathrm{~cm}$, respectively. These dimensions are much smaller than those obtained in other studies, as the authors did not measure the maximal length of the spleen as authors did in other studies, but rather the true superior to inferior length. This study further found that spleen size correlated poorly with height in the general population ${ }^{(37,38)}$. To determine normal spleen dimensions, Hosey RG, et al. conducted a study in 2006 , in British journal of sports ${ }^{(11)}$. For this purpose, they recruited 631 athletes from the Division I university. It was observed that the mean spleen length was $10.65 \mathrm{~cm}$ and mean width equaled to $5.16 \mathrm{~cm}$. They correlated the size of the spleen of men with the spleens in women and found a significant correlation of spleen size with gender. Men had larger spleens than women had. They further determine the correlation of white-American with AfricanAmerican individuals. There was also a significant correlation among the spleen size of the white individual and African individuals. White-American population had significantly larger spleens than African-American subjects had. Baik and Kim, published their work in 2018, to

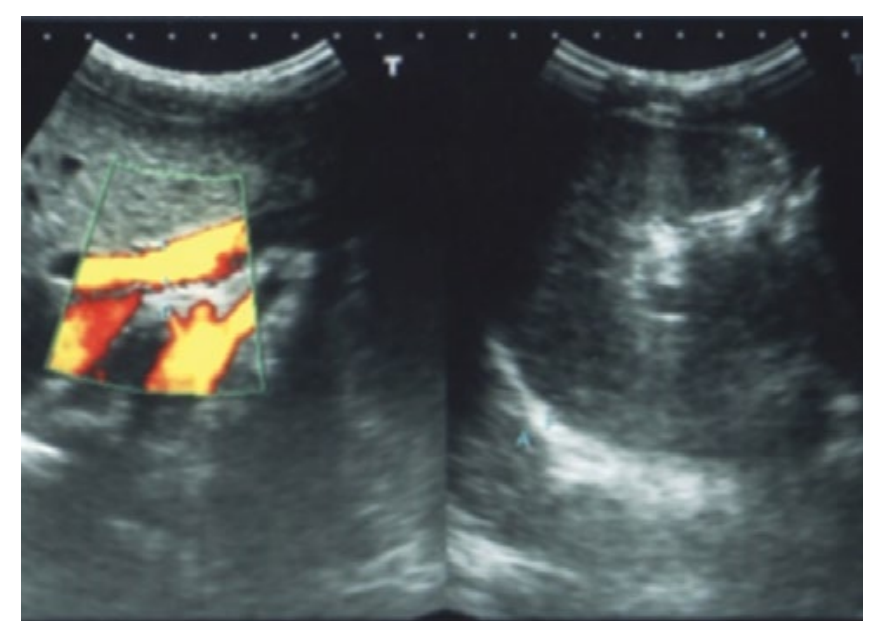

Fig. 4. Spleen size $=8.64 \mathrm{~cm}$, portal vein diameter $=8.7 \mathrm{~mm}$

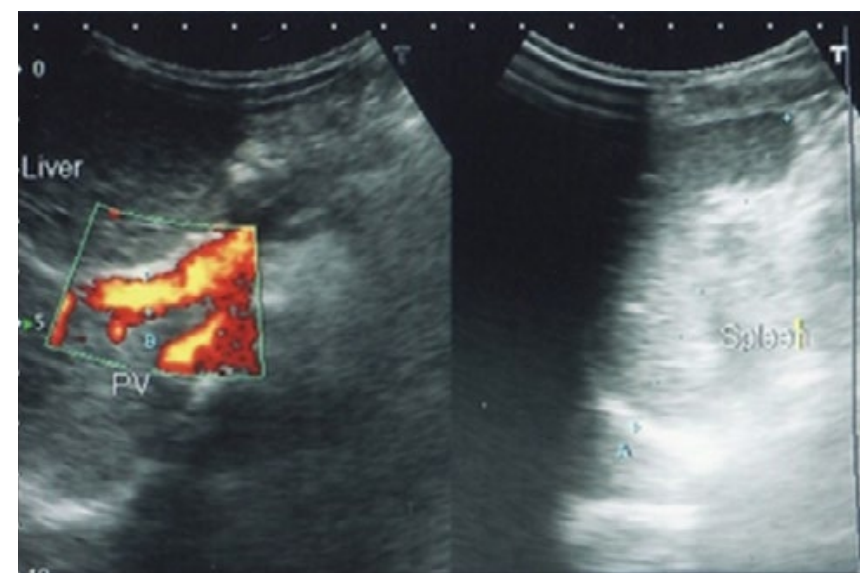

Fig. 5. Spleen size $=6.84 \mathrm{~cm}$, portal vein diameter $=6.8 \mathrm{~mm}$ 
determine the role of Doppler ultrasound in the diagnosis of chronic liver parenchymal disease.$^{10}$ Various factors, including the liver size, liver surface nodularity, spleen length, and splenic vein respiratory variation and portal vein blood flow velocity, showed a diagnostic accuracy ranging from $73 \%$ for the diagnosis of significant fibrosis, to $84 \%$ for severe fibrosis ${ }^{(39)}$.

To determine the clinical application of ultrasound, O'Donohue et al. conducted a study on 45 patients with chronic liver parenchymal disease and 49 healthy individuals $^{(9)}$. They established a normal reference value for spleen size and portal vein diameter from the normal controls. The mean spleen size was $10.7 \mathrm{~cm}$ in normal, it was significantly associated with height and weight but not with body mass and age. In male patients, spleen was significantly larger than in female patients. The mean portal vein diameter was $9.6 \mathrm{~mm}$. The mean spleen size was $16.0 \mathrm{~cm}$ in patients with chronic liver parenchymal disease, which is significantly larger than in normal individuals. The mean portal vein diameter in cirrhotic patients with standard deviation was $10.8 \mathrm{~mm}$. They concluded that spleen size and portal vein diameter increase with liver congestion. Subash Bhattarai, et al. observed 150 patients with chronic liver parenchymal disease, to determine the role of portal vein diameter and spleen size in the prognosis of gastroesophageal varices ${ }^{(40)}$. They observed mean portal vein diameter to be $10.800 \mathrm{~mm}$ in patients who do not suffer from varices, and $13.731 \mathrm{~mm}$ in patients with varices. Mean spleen size of patients with no varices

\section{References}

1. Richards JR, McGahan JP: Focused Assessment with Sonography in Trauma (FAST) in 2017: what radiologists can learn. Radiology 2017; 283: $30-48$.

2. Postema A, Idzenga T, Mischi M, Frinking P, de la Rosette J, Wijkstra H: Ultrasound modalities and quantification: developments of multiparametric ultrasonography, a new modality to detect, localize and target prostatic tumors. Curr Opin Urol 2015; 25: 191-197.

3. Manzoor I, Bacha R, Gilani SA: Diagnostic accuracy of sonoelastography in different diseases. J Ultrason 2018; 18: 29-36.

4. Bacha R, Gilani SA: Ultrasound diagnosis of spontaneous nephrocutaneous fistula. Ultrasound Q 2017; 33: 293-295.

5. Gilani SA: An overview of musculoskeletal ultrasound - A thirteen years experience in Pakistan. Perspectives in Medicine 2012; 1: 427-430.

6. Gilani SA: Musculoskeletal ultrasound. Cerebrovascular Diseases 2011; 31: 2-3.

7. Vancauwenberghe T, Snoeckx A, Vanbeckevoort D, Dymarkowski S, Vanhoenacker FM: Imaging of the spleen: what the clinician needs to know. Singapore Med J 2015; 56: 133-144.

8. Mazur R, Celmer M, Silicki J, Hołownia D, Pozowski P, Międzybrodzki K: Clinical applications of spleen ultrasound elastography - a review. J Ultrason 2018; 18: 37-41.

9. O'Donohue J, Ng C, Catnach S, Farrant P, Williams R: Diagnostic value of Doppler assessment of the hepatic and portal vessels and ultrasound of the spleen in liver disease. Eur J Gastroenterol Hepatol 2004; 16 : 147-155.

10. Baik SK, Kim MY: Diagnostic methods for cirrhosis and portal hypertension: imaging: ultrasound and doppler ultrasonography. In: Baik SK, Kim MY (ed.): Diagnostic Methods for Cirrhosis and Portal Hypertension. Springer, 2018: 139-147. was $12.67 \mathrm{~cm}$ and $15.367 \mathrm{~cm}$ in participant with varices. There was $92.72 \%$ sensitivity and $90 \%$ specificity for the portal vein diameter of $12.25 \mathrm{~mm}$, and $94.5 \%$ sensitivity, $75 \%$ specificity for the spleen size of $13.9 \mathrm{~cm}$, to predict gastro-esophageal varices. Our hypothesis was based on the concept of splenic length increase with an increase in portal vein diameter, the relation is shown in the scatterplot (Fig. 1). We observed similar results as obtained in previous studies, howeverwe correlated splenic size with portal vein diameter as shown in a series of figures (Fig. 2, Fig. 3, Fig. 4, Fig. 5). As there was a linear correlation between portal vein diameter and splenic length, therefore we present a logistic regression model and an example for elaboration (Formula in results).

\section{Conclusion}

Portal vein diameter and splenic craniocaudal length are linearly correlated. An increase in the spleen size may linearly predict an increase in the portal vein diameter in the case of chronic liver parenchymal disease (liver congestion).

\section{Conflict of interest}

Authors do not report any financial or personal connections with other persons or organizations, which might negatively affect the contents of this publication and/or claim authorship rights to this publication.
11. Hosey RG, Mattacola CG, Kriss V, Armsey T, Quarles J, Jagger J: Ultrasound assessment of spleen size in collegiate athletes. Br J Sports Med 2006; 40: 251-254.

12. Görg C, Eichkorn M, Zugmaier G: The small spleen: sonographic patterns of functional hyposplenia or asplenia. J Clin Ultrasound 2003; 31: 152-155.

13. de Porto AP, Lammers AJ, Bennink RJ, ten Berge IJ, Speelman P, Hoekstra JB: Assessment of splenic function. Eur J Clin Microbiol Infect Dis 2010; 29: 1465-1473.

14. Toma P, Granata C, Rossi A, Garaventa A: Multimodality imaging of Hodgkin disease and non-Hodgkin lymphomas in children. Radiographics 2007; 27: 1335-1354.

15. Chiorean L, Zdrenghea M, Badea R: Ultrasonography of the spleen. Pictorial essay. Med Ultrason 2014; 16: 48-59.

16. Schmidt G: Differential diagnosis in ultrasound imaging: a teaching Atlas. Thieme, 2011.

17. Virmani J, Kumar V, Kalra N, Khandelwal N: Prediction of liver cirrhosis based on multiresolution texture descriptors from B-mode ultrasound. Int J Convergence Computing 2013; 1: 19-37.

18. Rossi F, Leone VF, Vignoli M, Laddaga E, Terragni R: Use of contrastenhanced ultrasound for characterization of focal splenic lesions. Vet Radiol Ultrasound 2008; 49: 154-164.

19. Görg C, Riera-Knorrenschild J, Dietrich J: Pictorial review: colour doppler ultrasound flow patterns in the portal venous system. Br J Radiol 2002; 75: 919-929.

20. Park HS, Desser TS, Jeffrey RB, Kamaya A: Doppler ultrasound in liver cirrhosis: correlation of hepatic artery and portal vein measurements with model for end-stage liver disease score. J Ultrasound Med 2017; 36: 725-730. 
21. Gareeballah A, Hassan IA, Elzaki M, Ibraheem SS, Abelwahab B, Siddig A et al.: Measurement of normal portal vein using ultrasound in Sudanese. Glob Adv Res J Med Med Sci 2017; 6: 336-340.

22. Weis J, Schlosser S, Müller-Schilling M: Challenging HCC surveillance in a case with a history of peliosis hepatis and liver cirrhosis CHILD A due to a hypoplastic portal vein. Z Gastroenterol 2018; 56: E2-E89.

23. Coysh T, Zonoozi S, Jayasooriya N, Cargill Z, Burn-Murdoch A, Yalchin $\mathrm{M}$ et al.: PTU-073 Title: is portal vein diameter being reported in abdominal ultrasound scans of decompensated liver cirrhosis patients? Gut 2017; 66: 87-95.

24. Badi Y, Badro N, Dhawan S: Portal vein thrombosis: the overlooked association between pancreatic cancer and PVT. Oncol Cancer Case Rep 2017; 3: 1-2.

25. Roy S, Bhatt S, Rawal R, Tandon A, Meena N: Splenic vein thrombosis as a rare complication of disseminated tuberculosis - imaging diagnosis and case report. Pol J Radiol 2017; 82: 106-109.

26. Tokodai K, Miyagi S, Nakanishi C, Hara Y, Nakanishi W, Miyazawa K et al.: The utility of superb microvascular imaging for monitoring lowvelocity venous flow following pancreas transplantation: report of a case. J Med Ultrason 2018; 45: 171-174.

27. Christou N, Dib N, Chuffart E, Taibi A, Durand-Fontanier S, Valleix D et al.: Stepwise management of hepatocellular carcinoma associated with Abernethy syndrome. Clin Case Rep 2018; 6: 930-934.

28. Benson CB, Frates MC: Color Duplex Scanning of the Hepatoportal Circulation. In: Benson CB, Frates MC (ed.): Noninvasive vascular diagnosis. Springer, 2017: 623-646.

29. Mills A, Mellnick V: Imaging features of hepatic arterial and venous flow abnormalities. Clin Liver Dis 2018; 11: 27-32.

30. Luisa S, Vitale G, Sorbo AR, Maurizio P, Lodovico RG: Hepatic vein transit time of second-generation ultrasound contrast agent: new tool in the assessment of portal hypertension. J Ultrasound 2016; 20: 43-52.
31. Kievit L, Kræmer P, Hamilton-Dutoit S, Grønbæk H: Adult presentation of noncirrhotic portal hypertension and ascites following treatment for Wilms' tumor in childhood. Case Rep Gastroenterol 2018; 12: 56-62.

32. Endo M, Soroida Y, Sato M, Kobayashi T, Hikita H, Sato M et al.: Ultrasound evaluation of liver stiffness: accuracy of ultrasound imaging for the prediction of liver cirrhosis as evaluated using a liver stiffness measurement. J Med Dent Sci 2017; 64: 27-34.

33. Rosenberg HK, Markowitz RI, Kolberg H, Park C, Hubbard A, Bellah RD: Normal splenic size in infants and children: sonographic measurements. AJR Am J Roentgenol 1991; 157: 119-121.

34. Dittrich M, Milde S, Dinkel E, Baumann W, Weitzel D: Sonographic biometry of liver and spleen size in childhood. Pediatr Radiol 1983; 13: 206-211.

35. Konuş OL, Ozdemir A, Akkaya A, Erbaş G, Celik H, Işik S: Normal liver, spleen, and kidney dimensions in neonates, infants, and children: evaluation with sonography. AJR Am J Roentgenol 1998; 171: 1693-1698.

36. Frank K, Linhart P, Kortsik C, Wohlenberg H: Sonographic determination of spleen size: normal dimensions in adults with a healthy spleen. Ultraschall Med 1986; 7: 134-137.

37. Spielmann AL, DeLong DM, Kliewer MA: Sonographic evaluation of spleen size in tall healthy athletes. AJR Am J Roentgenol 2005; 184: 45-49.

38. Niederau C, Sonnenberg A, Müller JE, Erckenbrecht JF, Scholten T, Fritsch WP. Sonographic measurements of the normal liver, spleen, pancreas, and portal vein. Radiology 1983; 149: 537-540.

39. Aubé C, Oberti F, Korali N, Namour MA, Loisel D, Tanguy JY et al.: Ultrasonographic diagnosis of hepatic fibrosis or cirrhosis. J Hepatol 1999; 30: 472-478.

40. Bhattarai S, Gyawali M, Dewan KR, Shrestha G, Patowary BS, Sharma P: Study of portal vein diameter and spleen size by ultrasonography and their association with gastro-esophageal varices. Nepalese Journal of Radiology 2017; 4: 6-14. 